\title{
Rubella (German measles) revisited
}

\author{
Alexander KC Leung *, KL Hon, KF Leong
}

\section{A B S T R A C T}

Rubella is generally a mild and self-limited disease in children. During pregnancy, rubella can have potentially devastating effects on the developing fetus. Postnatal rubella is transmitted primarily by inhalation of virus-laden airborne droplets or direct contact with infected nasopharyngeal secretions. In susceptible pregnant women, the virus may cross the placenta and spread through the vascular system of the developing fetus. Postnatally acquired rubella typically begins with fever and lymphadenopathy, followed by an erythematous, maculopapular rash. The rash classically begins on the face, spreads cephalocaudally, becomes generalised within 24 hours, and disappears within 3 days. Maternal rubella, especially during early pregnancy, may lead to miscarriage, intrauterine fetal death, premature labour, intrauterine growth retardation, and congenital rubella syndrome. Cataracts, congenital heart defects, and sensorineural deafness are the classic triad of congenital rubella syndrome and they typically occur if the fetal infection occurs in the first 11 weeks of gestation. Laboratory confirmation of rubella virus infection can be based on a positive serological test for rubella-specific immunoglobulin $M$ antibody; a four-fold or greater increase in rubella-specific immunoglobulin $G$ titres between acute and convalescent sera; or detection of rubella virus RNA by reverse transcriptase-polymerase chain reaction. Treatment is mainly symptomatic. Universal childhood immunisation and vaccination of all susceptible patients with rubella vaccine to decrease circulation of the virus are cornerstones to prevention of rubella and, more importantly, congenital rubella syndrome.

\author{
Hong Kong Med J 2019;25:134-41

https://doi.org/10.12809/hkmj187785 \\ ${ }^{1}$ AKC Leung *, FRCP (UK), FRCPCH \\ ${ }^{2} \mathrm{KL}$ Hon, MD, FAAP \\ ${ }^{3}$ KF Leong, MB, BS, MRCPCH \\ 1 Department of Pediatrics, University of Calgary, Canada \\ 2 Department of Paediatrics, The Chinese University of Hong Kong, Hong \\ Kong \\ ${ }^{3}$ Department of Pediatric Institute, Kuala Lumpur General Hospital, \\ Malaysia \\ * Corresponding author: aleung@ucalgary.ca
}

\section{Introduction}

Rubella, also called German measles, is a communicable viral illness that typically begins with mild fever and lymphadenopathy followed by a characteristic brief appearance of a generalised erythematous, maculopapular rash. ${ }^{1}$ The disease was described by two German physicians, De Bergen in 1752 and Orlow in 1758, leading to the term "German measles". The term "rubella" was coined by Henry Veale, a Scottish physician in 1866. ${ }^{2}$ The word "rubella" is derived from the Latin word "rubellus" meaning "reddish" or "little red". In the absence of pregnancy, rubella is generally a mild, self-limited, and relatively benign infection. However, maternal rubella infection during the first trimester of pregnancy can be catastrophic and can result in fetal death or the birth of an infant with a constellation of congenital anomalies referred to as congenital rubella syndrome. ${ }^{3}$ This article provides an update on current knowledge about rubella and outlines an approach to its evaluation, prevention, and management.

A PubMed search was conducted in November 2018 using Clinical Queries with the key terms "Rubella" and "German measles". The search strategy included randomised controlled trials, meta-analyses, observational studies, clinical trials, and reviews. Only papers published in the English literature were included in this review. The information retrieved from the above search was used in the compilation of the present article.

\section{Aetiology}

The causative organism is the rubella virus, which is a non-arthropod-borne member of the family Togaviridae and the sole member of the genus Rubivirus. ${ }^{4,5}$ It is an enveloped, single-stranded, positive sense ribonucleic acid (RNA) virus. $^{6}$ The virus is easily destroyed by detergents, heat (temperature $>56^{\circ} \mathrm{C}$ ), ultraviolet light, and extremes of $\mathrm{pH}(\mathrm{pH}<6.8$ or $>8.1){ }^{4}$

The rubella virus is spherical, measuring 50 to $85 \mathrm{~nm}$ in diameter and shows pleomorphism. ${ }^{5}$ The viral genome encodes three structural proteins (C, E1, and E2) and two non-structural proteins (p90 and p150). ${ }^{6,7}$ The nucleocapsid is composed of the capsid protein $C$ which surrounds the singlestranded RNA.6,8 The outer envelope contains two glycosylated lipoproteins E1 and E2 which form transmembrane spikes anchored to the external layer of the membrane. ${ }^{5}$ The humoral response is induced particularly by these two glycosylated proteins 
which are important for the virulence of the virus. ${ }^{9}$ The E1 protein contains antigenic determinants that induce major immune responses. ${ }^{7}$ The protein is responsible for receptor binding, receptor-mediated endocytosis, and induction of membrane fusion. ${ }^{5,6}$ The E2 protein forms connections between rows of E1 proteins. ${ }^{5}$ The two non-structural proteins are related to transcription and replication which take place in the cytoplasm of the host cells..$^{5,6}$

\section{Epidemiology}

Humans are the only known reservoir for rubella infection. ${ }^{7,10}$ Postnatal rubella is transmitted primarily by inhalation of virus-laden airborne droplets or direct contact with infected nasopharyngeal secretions. ${ }^{1}$ Peak infection rates tend to occur in late winter and early spring., ${ }^{3,4}$

Prior to the introduction of the rubella vaccine, rubella was endemic worldwide, epidemics occurred at 6- to 9-year intervals, and major pandemics occurred every 10 to 30 years. ${ }^{6,11}$ During the last major pandemic from 1962 to 1965 , approximately $10 \%$ of pregnant women were infected and $30 \%$ of infants born to the infected mothers ultimately manifested features of congenital rubella syndrome. ${ }^{11}$ In the US alone, there were at least 12.5 million cases of clinically acquired rubella with more than 13000 fetal or early infant deaths, and 20000 cases of congenital rubella syndrome during the pandemic from 1962 to $1965 .{ }^{11}$ Since the introduction of the live attenuated rubella vaccine in 1969, rubella has become increasingly rare in North America and many developed countries. ${ }^{8}$ From 1969 to 1989, the annual number of reported cases of rubella in the US decreased $99.6 \%$ and the annual number of reported cases of congenital rubella syndrome decreased $97.4 \%{ }^{11}$ From 1998 to 2000, 2001 to 2004, and 2005 to 2011, the median number of reported rubella cases in the US was 272,13, and 11 per year, respectively. ${ }^{10}$ On 29 April 2015, the Pan American Health Organization officially declared elimination of rubella from the whole of the American region. ${ }^{12}$ Nowadays, rubella cases in developed countries are mainly "imported" from those countries where rubella is endemic and occur mostly in incompletely vaccinated or unvaccinated individuals. ${ }^{7,13}$

Globally, rubella continues to occur, with more than 100000 cases reported worldwide, especially in countries where routine childhood rubella vaccination is either not available or has just been recently introduced. ${ }^{14}$ In 2011, the World Health Organization (WHO) updated its guidance on the preferred strategy for introduction of rubellacontaining vaccine into the national immunisation schedules and recommended a vaccination campaign, targeting mainly children aged 9 months to 14 years. ${ }^{15}$ The number of WHO member states that include a rubella-containing vaccine in their

\section{再論風疹（德國麻疹） \\ 梁國柱、韓錦倫、梁健寬}

風疹一般屬輕微且自限性的兒童疾病。在懷孕期間，風疹可能對發育 中胎兒產生潛在的破壞性影響。產後風疹主要透過吸入帶病毒的飛沫 或接觸受感染鼻咽分泌物傳播。在易感孕婦中, 病毒可能穿過胎盤並 於發育中胎兒的血管系統內傳播。出生後患風疹常始於發燒和淋巴結 病, 伴似紅斑丘疹。皮疹一般從臉部開始, 24小時內由頭部上而下 蔓延然後融合, 並於 3 天內消退。母體風疹, 尤於懷乃早期可導致流 產、胎兒宮內死亡、早產、胎兒宮內發育遲緩和先天性風疹綜合徵。 白內障、先天性心臟病及神經性耳聾是先天性風疹綜合徵的典型三聯 徵, 常於胎兒在妊娠前 11 週出現感染時發生。經化驗確定的風疹病毒 感染可基於風疹特異性免疫球蛋白 $\mathrm{M}$ 抗體的陽性血清學檢測、急性和 恢復期血清間風疹特異性免疫球蛋白 $\mathrm{G}$ 增加4倍或以上、或通過逆轉 錄聚合酶鏈式反應檢測出風疹病毒核糖核酸。治療風疹以對症治療為 主。對風疹疫苗的所有易感兒童進行免疫和注射疫苗以減少病毒傳播 是預防風疹, 更重要的是, 先天性風疹綜合徵的基石。

routine childhood immunisation schedule has increased from 83 (43\%) of 193, to 132 (68\%) of 194 , to $141(72.7 \%)$ of 194 , and to $152(78.4 \%)$ of 194 , in 1996, 2012, 2014, and 2016, respectively. ${ }^{16,17}$ This is encouraging as there was a net increase of 20 countries that introduced the rubella-containing in their routine childhood immunisation schedule from 2012 to 2016. Despite this, intermittent rubella outbreaks continue to occur in some parts of the world, even in countries with a national immunisation if there is a substantial proportion of the population that are susceptible. ${ }^{8,18}$ The recent outbreak of rubella in Japan can be primarily attributed to susceptible men who were not included in the initial rubella immunisation schedule as the initial immunisation strategy provided rubella vaccine only to adolescent girls. ${ }^{5,8}$ In 2018, there were 2186 cases of rubella in Japan as of 29 November with more than $70 \%$ of cases reported in Tokyo and its surrounding prefectures. This is a significant increase from 1103 cases of rubella reported on 7 October $2018 .{ }^{19}$ As of 22 October 2018, the Centre for Health Protection of the Department of Health in Hong Kong recorded only six local cases of rubella infection in 2018 affecting two male and four female patients with age ranging from 3 to 65 years. ${ }^{20}$

In children, rubella affects both sexes equally whereas in adults, rubella affects more women than men. In the pre-vaccine era, rubella was most common in children aged 5 to 9 years. ${ }^{6,716}$ Currently, individuals aged $\geq 20$ years account for most reported cases. ${ }^{11}$ Risk factors for rubella include partially vaccinated or unvaccinated individuals, travelling to endemic areas, exposure to household members with rubella, and immunodeficiency. ${ }^{21,22}$ 


\section{Pathogenesis}

Postnatally acquired rubella is transmitted mainly via inhalation of aerosolised particles from the respiratory tract secretions of an infected individual. ${ }^{8}$ The virus infects cells in the upper respiratory tract of the susceptible host through receptor-mediated endocytosis. ${ }^{6,23}$ Initial replication occurs in the nasopharyngeal cells and lymphoid tissue of the nasopharynx and upper respiratory tract. ${ }^{6,8,23}$ Infected individuals may shed virus from the oropharynx and are contagious before the infection becomes clinically evident. ${ }^{8}$ Viraemia occurs 5 to 7 days after inoculation, disseminating the virus to multiple organs including the skin, lymph nodes, and, in a gravid patient, the placenta. ${ }^{8,9}$ The maculopapular rash occurs 2 to 8 days after the onset of viraemia and resolves as the humoral immune response develops and at this stage, the viraemia is terminated. 6,23

Maternal immunity, either naturally derived or after vaccination, is generally protective against intrauterine rubella infection. ${ }^{24}$ In a susceptible gravid patient, after infecting the placenta, the virus may cross the placenta, and spread through the vascular system of the developing fetus. ${ }^{6,14,25}$ Fetal damage may result from necrosis in the epithelium of chorionic villi, direct viral damage of infected cells by apoptosis, viral inhibition of mitosis and restricted development of precursor cells, and cytopathic damage to endothelial cells of blood vessels with resultant ischaemia in developing organs. ${ }^{14,23-25}$ Maternal rubella infection during pregnancy does not always result in vertical transmission of the virus to the fetus. ${ }^{9}$ The risk of fetal infection varies depending upon the time of maternal infection. ${ }^{11,25}$ Fetal infection rates are approximately $80 \%$ in the first trimester, $25 \%$ in the late second trimester, $35 \%$ at 27 to 30 weeks' gestation, and close to $100 \%$ beyond 36 weeks' gestation. ${ }^{10,11,24}$ It is important to note that although a fetus becomes infected, fetal malformation may not necessarily develop. ${ }^{11}$ The estimated risk for fetal malformation is approximately $90 \%, 33 \%, 11 \%, 24 \%$ and $0 \%$ when maternal infection occurs before 11 weeks, at 11 to 12 weeks, at 13 to 14 weeks, at 15 to 16 weeks, and after 20 weeks of gestation, respectively. ${ }^{10,24,25}$ This can be explained by passive transfer of maternal antibodies and by development of fetal humoral and cell-mediated immune responses with time. ${ }^{23}$

\section{Clinical manifestations}

\section{Postnatally acquired rubella}

The incubation period for postnatally acquired rubella is approximately 14 to 21 days (usually 16 to 18 days) after exposure to an individual with rubella. ${ }^{1}$ Approximately $25 \%$ to $50 \%$ of patients are asymptomatic (subclinical infection). ${ }^{1,4,10,24}$ The period of infectivity is maximal 7 days before to 7 days after onset of rash, coinciding with peak levels of rubella virus in the respiratory tract and viraemia which facilitate transmission. ${ }^{1,6,24}$

Prodromal symptoms typically precede the rash by 1 to 5 days. ${ }^{6,24}$ The symptoms, though common in adolescents and adults, are unusual in young children. ${ }^{3,6,8}$ The prodromal illness is characterised by low-grade fever, anorexia, nausea, malaise, lethargy, coryza, cough, headaches, nonexudative conjunctivitis, sore throat, myalgia, and tender lymph nodes. ${ }^{4}$ The lymphadenopathy typically involves retroauricular, suboccipital, and posterior cervical lymph nodes which often become more pronounced with the onset of rash (Fig 1). ${ }^{1,3,8}$ At times, the lymphadenopathy can be generalised. ${ }^{1,10}$ In approximately $20 \%$ of cases, petechiae can be observed on the soft palate (Forchheimer spots). ${ }^{6,8}$

The exanthem consists of pinpoint erythematous, maculopapules which classically begin on the face, spread caudally to the trunk and extremities, and become generalised within 24 hours (Fig 2). ${ }^{24}$ It is not unusual for the rash to be mildly pruritic. ${ }^{24}$ Occasionally, the rash is scarlatiniform or purpuric. ${ }^{7}$ The rash usually lasts for 3 days and fades in the same directional pattern as it appears. ${ }^{3,24}$

\section{Congenital rubella syndrome}

Congenital rubella syndrome may result from

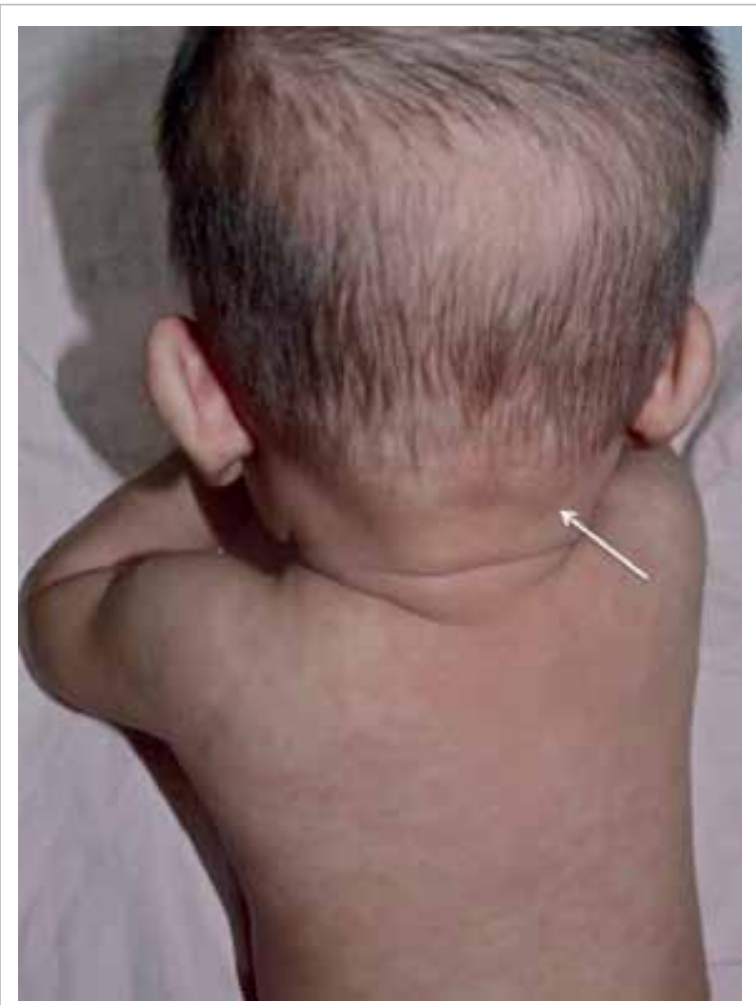

FIG I. Photograph of a 2-year-old boy with rubella showing bilateral suboccipital lymph nodes and a maculopapular rash on the back. One of the lymph nodes is indicated by a white arrow 


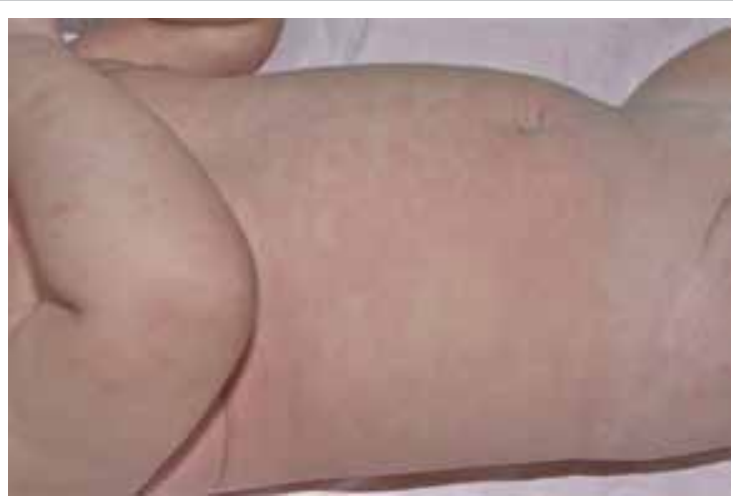

FIG 2. Photograph of a 2-year-old boy with rubella showing generalised erythematous maculopapular rash on the trunk and extremities. The rash started on the face and spread cephalocaudally to the trunk and extremities maternal rubella infection during embryogenesis. ${ }^{14}$ Cataracts, congenital heart defects, and sensorineural deafness are the classic triad of congenital rubella syndrome and they typically occur if the fetal infection occurs in the first 11 weeks of gestation. ${ }^{7,25,26}$

Ophthalmic abnormalities including cataracts (Fig 3), pigmentary retinopathy, infantile glaucoma, cloudy cornea, chorioretinitis, iris hypoplasia, lacrimal drainage anomalies, and microphthalmia occur in approximately $40 \%$ of cases.$^{4,5,7,25-28}$ Cataracts occur in approximately $25 \%$ of children with congenital rubella syndrome and they are bilateral in approximately $50 \%$ of cases. ${ }^{4,25}$ Congenital rubella syndrome is the most common cause of congenital cataracts. ${ }^{13}$ Pigmentary retinopathy is traditionally characterised by a salt and pepper appearance or a mottled, blotchy, irregular pigmentation in the fundus. ${ }^{11,27}$

Patent ductus arteriosus and peripheral pulmonary artery stenosis occur in approximately $20 \%$ and $12 \%$ of patients with congenital rubella syndrome, respectively. ${ }^{25}$ Other cardiovascular defects such as pulmonary artery hypoplasia, pulmonary valvular stenosis, aortic valve stenosis, coarctation of the aorta, atrial septal defect, ventricular septal defect, and tetralogy of Fallot have also been reported.,14,25

Hearing impairment occurs in approximately $60 \%$ of patients and is usually sensorineural and bilateral. ${ }^{7,25}$ At times, hearing impairment may be the sole manifestation of congenital rubella syndrome. ${ }^{29}$ The hearing impairment ranges from mild to severe, may not be apparent until the second year of life and beyond, and may progress over time. ${ }^{25}$

During the neonatal period, congenital rubella may produce a myriad of clinical features and conditions. These include prematurity, intrauterine growth retardation, microcephaly, haemolytic anaemia, thrombocytopenia, purpuric rash, jaundice,

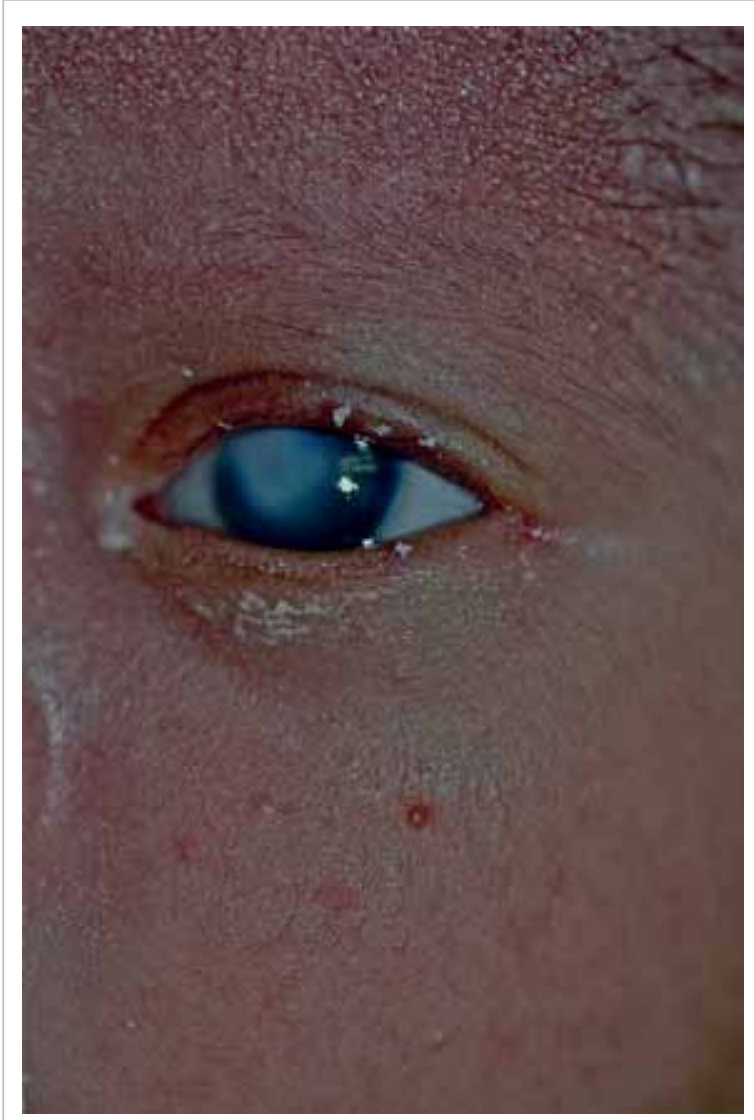

FIG 3. Photograph of a 7-month-old girl with a congenital cataract in the left eye due to congenital rubella syndrome

hepatitis, hepatomegaly, splenomegaly, "blueberry muffin" spots (sites of dermal erythropoiesis, Figs 4 and 5), hypotonia, bulging anterior fontanelle, constricted maxillary arch, high palate, interstitial pneumonia, myocarditis, myositis, nephritis, meningoencephalitis, and striated radiolucencies in the long bone ("celery stalk" lesions)., 4,7,25,30-35 Many of these features are transient and may resolve spontaneously over days or weeks. ${ }^{25}$

Delayed manifestations, in addition to sensorineural hearing impairment, include mental retardation, psychomotor retardation, speech delay, attention deficit hyperactivity syndrome, autism, behavioural disorders, progressive encephalopathy, insulin-dependent diabetes mellitus, thyroid dysfunction (hypothyroidism, hyperthyroidism, thyroiditis), Addison disease, growth hormone deficiency, and immunological defects. ${ }^{4,5,25,36-38}$

\section{Complications}

The most common complication of postnatal rubella is arthralgia/arthritis, which occurs in 60\% to $70 \%$ of teenagers and adult women about 1 week after the rash. ${ }^{8,23,24}$ The arthralgia/arthritis usually lasts 3 to 4 days but may persist for 1 month. ${ }^{7}$ 


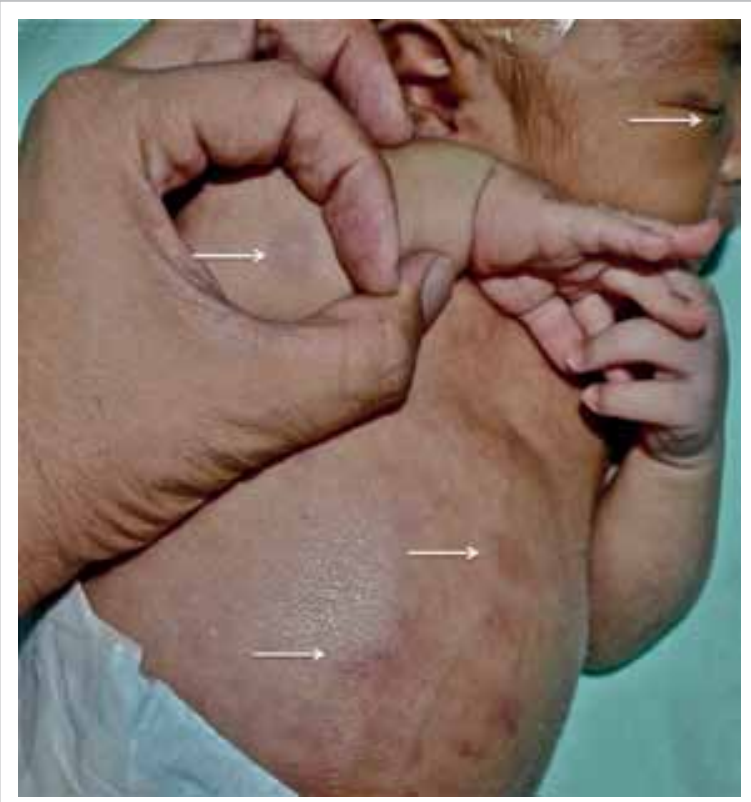

FIG 4. Photograph of a 2-week-old infant boy with congenital rubella syndrome presenting with "blueberry muffin" spots (arrows) manifested as non-blanching blue/ purple macules and nodules on the right lower eyelid, upper limbs and abdomen

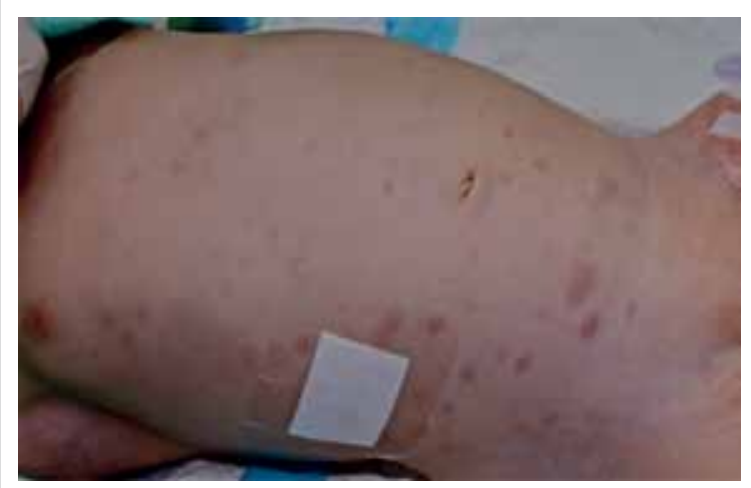

FIG 5. Photograph of a 2-week-old infant boy with congenital rubella syndrome presenting with "blueberry muffin" spots manifested as generalised non-blanching erythematous to bluish macules and nodules on the abdomen

Typically, the wrists, fingers, knees, and ankles are affected symmetrically. ${ }^{8,24}$ Morning stiffness may also occur. ${ }^{10}$ Arthralgia/arthritis is uncommon in children and adult men. ${ }^{4,8}$ Other rare complications include carpal tunnel syndrome, tenosynovitis, thrombocytopenia, purpura, haemolytic anaemia, haemolytic uraemia syndrome, myocarditis, pericarditis, hepatitis, orchitis, retinopathy, uveitis, Guillain-Barré syndrome, and post-infectious encephalopathy. ${ }^{7,23,24,39-42}$
In addition to congenital rubella syndrome, maternal rubella, especially during early pregnancy, may lead to miscarriage, intrauterine fetal death, premature labour, and intrauterine growth retardation. ${ }^{14,25}$ Individuals with congenital rubella syndrome are at risk for deafness, blindness, hypertension, cardiac failure, academic failure, reduced life expectancy and, in female patients, early menopause and osteoporosis. ${ }^{37}$ The disabilities and financial burden associated with congenital rubella syndrome have an adverse effect on quality of life.

\section{Diagnosis and laboratory investigations}

Rubella should be suspected in a patient with fever, erythematous maculopapular (non-vesicular) rash spreading cephalocaudally from the face downwards, and retroauricular/suboccipital/posterior cervical lymphadenopathy, especially in the presence of arthralgia/arthritis. This is especially so if there is a history of exposure to rubella, travel to an endemic area, or during an outbreak of rubella in an individual without immunity to rubella.

Generally, clinical diagnosis of rubella is unreliable because the clinical manifestations can be mild and non-specific especially in young children. In addition, there are many other viral infections having similar clinical features. Laboratory confirmation of rubella virus infection is therefore essential. The diagnosis of a recent postnatal rubella infection can be based on a positive serological test for rubella-specific immunoglobulin M (IgM) antibody in a single sample or a four-fold or greater increase in rubella-specific immunoglobulin (IgG) titres between acute and convalescent sera drawn 2 to 3 weeks apart. $5,6,8,824$ Among all the serologic tests available, enzyme linked immunoassays (ELISA) are most commonly used to measure rubella-specific IgG and IgM because they are very sensitive, highly specific, technically easy to perform, rapid, and relatively inexpensive. ${ }^{8,10}$ Rubella-specific IgM antibody is present in approximately $50 \%$ of patients on the day of appearance of the rash but in almost all the cases 5 days after the onset of rash; the IgM antibody tends to persist $\geq 8$ weeks. ${ }^{5,8}$ As such, rubellaspecific IgM antibody might be falsely negative if the test is conducted early. In contrast, false positive results may rarely occur in patients with heterophile antibodies, rheumatoid factors, parvovirus B19 infection, and cytomegalovirus infection. ${ }^{1,8}$ The use of IgM-capture ELISA rather than indirect IgM ELISA may reduce the occurrence of false positive results. ${ }^{1,8}$ When the first serum sample was collected months after clinical symptoms, avidity (strength of antigen-antibody binding) test of rubella-specific IgG antibody, if available, can be used to differentiate a recent primary infection from a past infection or reinfection. ${ }^{3,5,8}$ Low avidity anti-rubella IgG suggests 
recent primary rubella infection while high avidity is consistent with previous rubella vaccination, past rubella infection, or reinfection. ${ }^{3,5,7,8}$

Although rubella virus can be isolated most consistently from nasopharyngeal and throat specimens, viral culture is generally not necessary because viral culture is expensive, time-consuming, and not readily available. Rubella virus culture is done mainly for academic and epidemiological purposes to facilitate surveillance during outbreaks. ${ }^{10}$ Rubella virus RNA testing by real-time reverse transcriptasepolymerase chain reaction (RT-PCR), if available, may be performed for diagnosis and genotype identification. ${ }^{1,10}$

The diagnosis of congenital rubella syndrome can be confirmed by the detection of rubella-specific IgM antibody in the cord blood or in the neonatal serum collected within the first 6 months of life. ${ }^{1,25}$ In infants older than 3 months, a negative IgM does not exclude a congenital rubella infection although a positive test does support the diagnosis..$^{23,25}$ Congenital rubella infection can also be confirmed by demonstrating persistent or increasing serum concentrations of rubella-specific IgG over the first 7 to 11 months of life. ${ }^{1}$ Detection of rubella virus RNA by RT-PCR in nasopharyngeal swab or urine provides laboratory evidence of congenital rubella syndrome. . $^{4,8,25}$

\section{Differential diagnosis}

The differential diagnosis includes measles, scarlet fever, roseola infantum (exanthem subitum), erythema infectiosum (fifth disease), infectious mononucleosis, mycoplasma infection, rashassociated enteroviral infection, Kawasaki disease, drug eruption, contact dermatitis, dengue, toxoplasmosis, cytomegalovirus infection, Zika virus infection, West Nile fever, Ross River fever, and Chikungunya fever. ${ }^{8,14,21,23,43,44}$

\section{Management}

Treatment of postnatally acquired rubella in a nongravid individual is mainly symptomatic and consists of the use of non-steroidal anti-inflammatory drugs for severe arthralgia/arthritis. ${ }^{10}$ In a gravid individual with rubella infection, management depends on the gestation age at the time of infection. ${ }^{7}$ If the infection occurs before 20 weeks' gestation, the fetus is at risk for malformation. ${ }^{10,24,25}$ Termination of pregnancy should be discussed as an option based on local legislation. Immune globulin administered intramuscularly or intravenously should be considered for susceptible women with known rubella exposure in early pregnancy for whom termination of pregnancy is not an option. ${ }^{4,6,24}$

Treatment of children with congenital rubella syndrome should be symptomatic and organ-specific and directed to improve the patient outcome and quality of life. Children with congenital rubella syndrome often present with a broad range of problems and therefore will benefit from a multidisciplinary approach. Consultations with, among others, a paediatrician, ophthalmologist, cardiologist, otorhinolaryngologist, and speech pathologist should be considered. Because children with congenital rubella syndrome are at risk for delayed manifestations, long-term audiologic, ophthalmic, and neurodevelopmental follow-up is indicated for early identification of these disorders. Early intervention is important to educate the family, organise the most appropriate educational placement, and plan specialist referral and follow-up.

\section{Prevention}

\section{Immunisation}

Universal childhood immunisation and vaccination of all susceptible patients with rubella vaccine to decrease circulation of the virus are the cornerstones to prevention of rubella and, more importantly, congenital rubella syndrome. The current strategy is to immunise all children aged 12 to 15 months and again at age 4 to 6 years with rubella vaccine, according to recommendations for routine measles, mumps, rubella, and varicella vaccination. ${ }^{1}$ One dose of rubella vaccine given at or after age 1 year is $95 \%$ effective in protecting against rubella infection whereas two doses given at appropriate intervals is close to $100 \%$ effective. ${ }^{4,5,8,14}$ Women of childbearing age without documentation of rubella immunity should get vaccinated before they become pregnant. ${ }^{1,14}$ Women receiving rubella vaccine should be advised to avoid pregnancy for 1 month after rubella vaccination., ${ }^{4,10}$ Routine prenatal screening for immunity to rubella should be performed. ${ }^{1}$ Rubella susceptible women should receive measlesmumps-rubella (MMR) vaccine in the immediate postpartum period as a significant number of these individuals are also susceptible to measles and/or mumps. ${ }^{10}$

Globally, the most commonly used rubella vaccines contain a live attenuated RA 27/3 strain grown in human diploid cell cultures. ${ }^{1,8,24}$ China and Japan use BRD-2 and TO-336 strains, respectively. ${ }^{7}$ The vaccines, once administered, would replicate within the host to induce both humoral and cellular immunity. ${ }^{1,8,24}$ Rubella vaccines can be given subcutaneously as a single component (eg, in Russia and some African countries), but more often, as combination vaccines such as measles-mumpsrubella-varicella (MMRV) vaccine and MMR vaccine. ${ }^{8,10}$ The MMRV vaccine has similar safety profile and immunogenicity as the MMR vaccine except that MMRV vaccine has a two-fold increase in relative risk of febrile seizures. ${ }^{45}$ 
Rubella vaccines are generally safe, immunogenic, highly cost-effective, and well tolerated. ${ }^{5}$ Adverse effects usually occur 5 to 12 days post-vaccination and consist mainly of fever (15\%), rash (5\%), transient arthralgia/arthritis, and mild lymphadenopathy. ${ }^{1,710,24}$ Rare adverse effects include febrile seizures, parotiditis, thrombocytopenic purpura, anterior uveitis, cataract, anaphylaxis, and encephalitis. ${ }^{7,46}$

Rubella vaccine given to a nursing mother does not affect the safety of breastfeeding both for the mother and infant. ${ }^{1}$ As such, breastfeeding is not a contra-indication to rubella immunisation. ${ }^{1}$ Contraindications for rubella vaccination include febrile illness, moderate/severe illness, immunodeficiency, hypersensitivity to any component of the vaccine including gelatine and neomycin, confirmed history of an anaphylactic reaction to a previous rubellacontaining vaccine, and pregnancy.,10 However, inadvertent administration of a rubella-containing vaccine to pregnant mothers is not known to cause fetal and/or maternal complications. ${ }^{4,10,24}$ Rubella vaccination should be deferred for at least 4 weeks in those individuals with recent use of high-dose corticosteroids ( $>2 \mathrm{mg} / \mathrm{kg}$ or $20 \mathrm{mg} /$ day) for $\geq 14$ days or recent administration of immunoglobulin or blood products. ${ }^{1}$ The rubella vaccine can be given at the same time as other live vaccines, but should be deferred for 3 weeks after another live vaccine has been given. ${ }^{4}$

\section{Infection control}

Confirmed cases of rubella should be excluded from day care or school for at least 7 days after onset of the rash.1 Proper hand washing technique and droplet precautions should be emphasised. ${ }^{14}$

Children with congenital rubella syndrome can transmit the disease as long as they are shedding the virus. Approximately $20 \%$ of children with congenital rubella syndrome may still be shedding the virus from the pharynx at aged 1 year and therefore are contagious. ${ }^{3}$ These individuals should be isolated to avoid the spread of the infection until two throat swab or urine cultures obtained at least 1 month apart are negative for the rubella virus. ${ }^{1}$ Only healthcare providers with immunity to rubella should be involved in the care of these patients.

\section{Prognosis}

Postnatally acquired rubella is generally a mild, self-limited, and relatively benign infection without consequences in most cases. ${ }^{35}$ However, infection in early pregnancy may lead to miscarriage, intrauterine fetal death, premature labour, and congenital rubella syndrome. The prognosis of children with congenital rubella syndrome varies, depending on the severity and number of organs affected. Infants with thrombocytopenia, hepatosplenomegaly, interstitial pneumonia, and pulmonary hypertension have a high risk of mortality. ${ }^{34,47}$ Of those who develop thrombocytopenia and hepatosplenomegaly in the neonatal period, approximately $15 \%$ die within the first year of life. ${ }^{3}$

\section{Conclusions}

Apart from congenital infection, rubella is generally a mild and self-limited disease in children. Rubella when acquired by a pregnant mother in an early stage of the pregnancy can have catastrophic effects on the developing fetus and may result in miscarriage, intrauterine fetal death, premature labour, intrauterine growth retardation, and congenital rubella syndrome. To eliminate rubella from a population, universal childhood immunisation and vaccination of all susceptible individuals with rubella vaccine is required. Although rubella has been eliminated from most developed countries, physicians should remain vigilant in recognising both postnatal rubella and congenital rubella syndrome because rubella cases can be "imported" from those countries where rubella is endemic.

\section{Author contributions}

All authors have made substantial contributions to the concept or design of the study, acquisition of data, analysis or interpretation of data, drafting of the manuscript, and critical revision for important intellectual content. All authors had full access to the data, contributed to the study, approved the final version for publication, and take responsibility for its accuracy and integrity.

\section{Conflicts of interest}

All authors have disclosed no conflict of interest.

\section{Funding/support}

This research received no specific grant from any funding agency in the public, commercial, or not-for-profit sectors.

\section{Ethics approval}

All patients were treated in accordance with the Declaration of Helsinki. The parents of all patients provided written informed consent for photographs to be taken and published.

\section{References}

1. Kimberlin DW, Brady MT, Jackson MA, Long SS, editors. Red Book: 2018 Report of the Committee on Infectious Diseases. 31st ed. Itasca: American Academy of Pediatrics; 2018: 705-11.

2. Veale H. History of an epidemic of Rötheln with observations on its pathology. Edinb Med J 1866;12:40414.

3. Drutz JE. Rubella. Pediatr Rev 2010;31:129-30.

4. Best JM. Rubella. Semin Fetal Neonatal Med 2007;12:18292.

5. Lambert N, Strebel P, Orenstein W, Icenogle J, Poland GA. Rubella. Lancet 2015;385:2297-307. 
6. Tyor W, Harrison T. Mumps and rubella. Handb Clin Neurol 2014;123:591-600.

7. Bouthry E, Picone O, Hamdi G, Grangeot-Keros L, Ayoubi JM, Vauloup-Fellous C. Rubella and pregnancy: diagnosis, management and outcomes. Prenat Diagn 2014;34:124653.

8. Edwards MS. Rubella. Available from: https://www. uptodate.com/contents/rubella. Accessed 5 Dec 2018

9. De Santis M, Cavaliere AF, Straface G, Caruso A. Rubella infection in pregnancy. Reprod Toxicol 2006;21:390-8.

10. Riley LE. Rubella in pregnancy. Available from: https:// www.uptodate.com/contents/rubella-in-pregnancy. Accessed 10 Dec 2018.

11. Duszak RS. Congenital rubella syndrome-major review. Optometry 2009;80:36-43.

12. Kirby T. Rubella is eliminated from the Americas. Lancet Infect Dis 2015;15:768-9.

13. Fang J, Agrawal A, Gowtham S, et al. Case report: congenital rubella syndrome: a rare but persistent concern in the United States. J Perinatol 2013;33:899-902.

14. Shukla S, Maraqa NF. Congenital rubella. StatPearls. Available from: https://www.ncbi.nlm.nih.gov/books/ NBK507879/. Accessed 10 Jan 2019.

15. Rubella vaccines: WHO position paper. Wkly Epidemiol Rec 2011;86:301-16.

16. Martínez-Quintana E, Castillo-Solórzano C, Torner N, Rodríguez-González F. Congenital rubella syndrome: a matter of concern. Rev Panam Salud Publica 2015;37:17986.

17. Grant GB, Reef SE, Patel M, Knapp JK, Dabbagh A. Progress in rubella and congenital rubella syndrome control and elimination-Worldwide, 2000-2016. MMWR Morb Mortal Wkly Rep 2017;66:1256-60.

18. Chang C, Ma H, Liang W, et al. Rubella outbreak and outbreak management in a school setting, China, 2014. Hum Vaccin Immunother 2017;13:772-5.

19. Hackett DW. Japan's rubella outbreak reaches 2,186 cases. 29 Nov 2018. Available from: https://www. precisionvaccinations.com/travel-alert-level-2-remainsactive-regarding-japan\%E2\%80\%99s-rubella-outbreak. Accessed 14 Mar 2019.

20. Hong Kong SAR Government. Press release. Public and travellers urged to guard against infectious diseases during Lunar New Year holiday. Available from: https://www. info.gov.hk/gia/general/201901/25/P2019012500443.htm. Accessed 10 Nov 2019.

21. Chan T, MacFadden DR, Leis JA. Rubella in a returned traveller. CMAJ 2016;188:363-6.

22. Sadlier C, Carr A, Bergin C. High levels of susceptibility to measles, mumps and rubella (MMR) in HIV-infected individuals in Ireland. J Infect 2016;73:84-6.

23. Banatvala JE, Brown DW. Rubella. Lancet 2004;363:112737.

24. Dontigny L, Arsenault MY, Martel MJ. No. 203-Rubella in pregnancy. J Obstet Gynaecol Can 2018;40:e615-21.

25. Dobson SR. Congenital rubella syndrome: clinical features and diagnosis. Available from: https://www.uptodate.com/ contents/congenital-rubella-syndrome-clinical-featuresand-diagnosis/print. Accessed 15 Dec 2018.

26. Cordier AG, Vauloup-Fellous C, Grangeot-Keros L, et al. Pitfalls in the diagnosis of congenital rubella syndrome in the first trimester of pregnancy. Prenat Diagn 2012;32:4967 .
27. Bypareddy R, Chawla R, Azad SV, Khokhar S. Rubella cataract and retinopathy. BMJ Case Rep 2016;2016. pii: bcr2016216112.

28. Gupta S, Ali MJ, Naik MN. Lacrimal drainage anomalies in congenital rubella syndrome. Clin Ophthalmol 2017;11:1975-7.

29. Nagasawa K, Ishiwada N, Ogura A, et al. Congenital rubella syndrome: a case report on changes in viral load and rubella antibody titers. Pediatrics 2016;137. pii: e20153333.

30. Ahuja R, Shigli AL, Thakur G, Jain U. Dental manifestations of congenital rubella syndrome. BMJ Case Rep 2015;2015. pii: bcr2015209382.

31. Ajij M, Nangia S, Dubey BS. Congenital rubella syndrome with blueberry muffin lesions and extensive metaphysitis. J Clin Diagn Res 2014;8:PD03-4.

32. Gandhi N, Mendiratta V, Shukla S, Rawat R, Rana S, Chander R. Violaceous maculopapular rash in a newborn: Congenital rubella syndrome. Indian $J$ Dermatol 2015;60:521.

33. Kumar D, Jajoo M. Congenital rubella syndrome: an unusual cause of neonatal fulminant hepatic failure. Trop Doct 2018;48:66-8.

34. Mizuno Y, Yokoi K, Suzuki S. Congenital rubella syndrome with death from interstitial pneumonia. Pediatr Int 2016;58:490-3.

35. Yazigi A, De Pecoulas AE, Vauloup-Fellous C, GrangeotKeros L, Ayoubi JM, Picone O. Fetal and neonatal abnormalities due to congenital rubella syndrome: a review of literature. J Matern Fetal Neonatal Med 2017;30:274-8.

36. Chauhan N, Sen MS, Jhanda S, Grover S. Psychiatric manifestations of congenital rubella syndrome: a case report and review of literature. J Pediatr Neurosci 2016;11:137-9.

37. Dammeyer J. Congenital rubella syndrome and delayed manifestations. Int J Pediatr Otorhinolaryngol 2010;74:1067-70.

38. Hutton J. Does rubella cause autism: a 2015 reappraisal? Front Hum Neurosci 2016;10:25.

39. Bharadwaj SD, Sahay RR, Yadav PD, et al. Acute encephalitis with atypical presentation of rubella in family cluster, India. Emerg Infect Dis 2018;24:1923-5.

40. Chaari A, Bahloul M, Berrajah L, et al. Childhood rubella encephalitis: diagnosis, management, and outcome. J Child Neurol 2014;29:49-53.

41. Kamiya K, Nishio E, Horio A, Tokura Y. Unusual clinical manifestations of rubella in the elderly. Int J Dermatol 2016;55:e371-2.

42. Robson WL, Leung AK, Kaplan BS. Hemolytic-uremic syndrome. Curr Probl Pediatr 1993;23:16-33.

43. Leung AK, Hon KL, Leong KF, Sergi CM. Measles: a disease often forgotten but not gone. Hong Kong Med J 2018;24:512-20.

44. Vaidya SR, Raut CG, Jadhav SM. Laboratory confirmation of rubella infection in suspected measles cases. J Med Virol 2016;88:1685-9.

45. Leung AK, Hon KL, Leung TN. Febrile seizures: an overview. Drugs Context 2018;7:212536.

46. Ferrini W, Aubert V, Balmer A, Munier FL, Abouzeid H. Anterior uveitis and cataract after rubella vaccination: a case report of a 12-month-old girl. Pediatrics 2013;132:e1035-8.

47. Toizumi M, Motomura H, Vo HM, et al. Mortality associated with pulmonary hypertension in congenital rubella syndrome. Pediatrics 2014;134:e519-26. 